Jurnal Indonesia Sosial Teknologi: p-ISSN: 2723 - 6609

e-ISSN : 2745 - 5254

Vol. 1, No. 3 Oktober 2020

\title{
PERBANDINGAN METODE PENDUKUNG KEPUTUSAN DALAM SELEKSI KONSULTAN DESAIN REKAYASA
}

\author{
Warkianto Widjaja \\ Universitas Kebangsaan Bandung \\ Email : warkiw62@gmail.com
}

\begin{abstract}
Abstact
In determining the engineering consultant, there are many criteria that must be possessed by the assigning company as a condition in determining the winner of the planning work auction. Each company must have criteria to determine the selected participant as the winner of the planning work auction. Planning work bidding is carried out by several companies to determine the most competent planning consultants in order to obtain good quality process and design results in terms of cost, quality and time. The engineering consultant selection criteria used were similar work experience from the company for the last 7 years, expert qualifications, understanding of the framework of reference, approach and methodology for the facility design concept and scheduling, supporting facilities owned, and exposure to design concepts in front of the jury. In this study, a case was appointed, namely looking for the best alternative and comparison of decision support methods based on predetermined criteria using the Topsis and methods Smart. The research was conducted by looking for the weight value for each criterion and the value of each criterion for each alternative company participating in the auction, then a ranking process was carried out to determine the superior alternative, namely the best engineering design consultant. The result of this research is information regarding the value ranking of all auction participants. The company participating in the auction with the best competency level is the A3 consulting firm, both obtained from the methods TOPSIS and SMART. Both methods give the same ranking order results for the highest alternative and the second with the highest order is A3, followed by Al.
\end{abstract}

Keyword : Topsis, Smart, auction, engineering design consultant

\section{Abstrak}

Dalam menentukan konsultan rekayasa, banyak sekali kriteria-kriteria yang harus dimiliki oleh perusahaan pemberi tugas sebagai syarat dalam menentukan pemenang lelang pekerjaan perencanaan. Masing-masing perusahaan pasti memiliki kriteria-kriteria untuk menentukan peserta yang terpilih sebagai pemenang lelang pekerjaan perencanaan tersebut. Pelaksanaan lelang pekerjaan perencanaan dilakukan oleh beberapa perusahaan untuk menentukan konsultan perencana yang paling kompeten sehingga didapat proses dan hasil desain yang bermutu baik dari segi biaya, mutu dan waktu. Kriteria seleksi konsultan rekayasa yang digunakan adalah pengalaman kerja sejenis dari perusahaan selama 7 tahun terakhir, kualifikasi tenaga ahli, pemahaman terhadap kerangka acuan kerja, pendekatan dan metodologi terhadap konsep desain fasilitas dan penjadwalan, fasilitas pendukung yang dimiliki, dan paparan konsep desain di depan juri. Pada penelitian ini diangkat suatu kasus yaitu mencari alternatif terbaik dan perbandingan metode pendukung keputusan bedasarkan kriteria-kriteria yang telah ditentukan menggunakan metode Topsis dan Smart. Penelitian 
dilakukan dengan mencari nilai bobot untuk setiap kriteria dan nilai masing masing kriteria untuk setiap alternatif perusahaan peserta lelang, kemudian dilakukan proses perankingan untuk menentukan alternatif yang unggul, yaitu konsultan desain rekayasa terbaik. Hasil dari penelitian ini adalah informasi mengenai peringkat nilai dari semua peserta lelang. Perusahaan peserta lelang dengan tingkat kompetensi terbaik yaitu perusahaan konsultan A3, baik yang didapat dari metode TOPSIS maupun SMART. Kedua metode memberikan hasil urutan ranking yang sama untuk alternatif tertinggi dan kedua dengan urutan dari yang paling tinggi $\mathrm{A} 3$, disusul A1.

Kata kunci: Topsis, Smart, lelang, konsultan desain rekayasa

\section{Pendahuluan}

Proses lelang yang bermutu memberikan pengaruh yang besar pada proses desain diantaranya adalah hasil desain yang baik. Namun terkadang kegiatan pekerjaan perencanaan tidak berjalan dengan efektif, dimana hal ini disebabkan oleh data identifikasi pelaksana pekerjaan desain rekayasa yang kurang akurat. Hasil perencanaan pengembangan yang baik pada suatu perusahaan menunjukan seberapa berhasilnya suatu perusahaan mendapatkan hasil desain rekayasa yang sesuai dengan tujuannya.

Dalam rangka meningkatkan arah pengembangan yang sesuai dengan studi rencana induk atau master plan, maka perusahaan melaksanakan berbagai kegiatan seperti kegiatan lelang pekerjaan desain rekayasa yang lebih terinci dan bermutu. Terkadang ditemukan terjadi kesalahan dalam menentukan kelayakan penerima pekerjaan desain rekayasa tersebut. Masalah seperti ketidaktepatan penentuan konsultan desain rekayasa tentunya harus segera diatasi dan dicari solusinya agar tidak terulang lagi pada kegiatan desain rekayasa yang lebih terinci di masa datang. (Suyantoro, 2017) Sehingga pihak yang menyelenggarakan lelang pekerjaan desain rekayasa membutuhkan informasi mengenai keadaan perusahaan peserta lelang baik dari aspek administratif maupun aspek teknis.

Setiap perusahaan membutuhkan penggunaan teknologi yang tepat sasaran dan perencanaan sistem informasi yang matang, menyeluruh dan total aksi di segala bagian kerja, didukung dengan sumber daya manusia yang mampu mengaplikasikan teknologi tersebut secara kontinuitas (Soipah, 2017). Kompetensi tenaga ahli, metodologi pelaksanaan desain rekayasa dan kemampuan inovasi merupakan hal-hal yang harus diprioritaskan untuk diberikan penilaian.

Melihat permasalahan tersebut maka perlu adanya suatu sistem yang dapat menentukan konsultan desain rekayasa yang terbaik. (Chamid \& Murti, 2017) Dalam penentuan konsultan desain rekayasa ini, digunakan beberapa indikator atau kriteria yang dianggap mampu mempengaruhi penentuan hasil desain rekayasa yang bermutu dengan biaya yang optimal.

Proses lelang yang bermutu memberikan pengaruh yang besar pada proses desain diantaranya adalah hasil desain yang baik. Namun terkadang kegiatan pekerjaan perencanaan tidak berjalan dengan efektif, dimana hal ini disebabkan oleh data identifikasi pelaksana pekerjaan desain rekayasa yang kurang akurat. (Daihani, 2001) 
Hasil perencanaan pengembangan yang baik pada suatu perusahaan menunjukan seberapa berhasilnya suatu perusahaan mendapatkan hasil desain rekayasa yang sesuai dengan tujuannya.

Dalam rangka meningkatkan arah pengembangan yang sesuai dengan studi rencana induk atau master plan, maka perusahaan melaksanakan berbagai kegiatan seperti kegiatan lelang pekerjaan desain rekayasa yang lebih terinci dan bermutu. Terkadang ditemukan terjadi kesalahan dalam menentukan kelayakan penerima pekerjaan desain rekayasa tersebut. (Widjaja, 2019) Masalah seperti ketidaktepatan penentuan konsultan desain rekayasa tentunya harus segera diatasi dan dicari solusinya agar tidak terulang lagi pada kegiatan desain rekayasa yang lebih terinci di masa datang. Sehingga pihak yang menyelenggarakan lelang pekerjaan desain rekayasa membutuhkan informasi mengenai keadaan perusahaan peserta lelang baik dari aspek administratif maupun aspek teknis.

Setiap perusahaan membutuhkan penggunaan teknologi yang tepat sasaran dan perencanaan sistem informasi yang matang, menyeluruh dan total aksi di segala bagian kerja, didukung dengan sumber daya manusia yang mampu mengaplikasikan teknologi tersebut secara kontinuitas (Soipah, 2017). Kompetensi tenaga ahli, metodologi pelaksanaan desain rekayasa dan kemampuan inovasi merupakan hal-hal yang harus diprioritaskan untuk diberikan penilaian.

Melihat permasalahan tersebut maka perlu adanya suatu sistem yang dapat menentukan konsultan desain rekayasa yang terbaik. Dalam penentuan konsultan desain rekayasa ini, digunakan beberapa indikator atau kriteria yang dianggap mampu mempengaruhi penentuan hasil desain rekayasa yang bermutu dengan biaya yang optimal.

Dimana informasi yang dihasilkan dapat membantu pihak pengambil keputusan dalam hal ini perusahaan pelaksana lelang dalam memilih atau menentukan konsultan desain rekayasa yang unggul. Perkembangan teknologi dan informasi, khususnya yang terjadi di Indonesia terjadi sangat dinamis. Perkembangan tersebut tentu saja berdampak pada segala bidang (Furqoni et al., 2020), termasuk dalam bidang industri konstruksi di Indonesia.

\section{Metode Penelitian}

\section{Tahapan Penelitian}

Tahap-tahap yang digunakan dalam penelitian ini ada 6 tahap yaitu penentuan kriteria, pengumpulan data, analisis data, pengolahan data dan perhitungan, analisis hasil, kesimpulan dan saran. Menurut (Sugiyono et al., 2017), teknik pengumpulan data merupakan cara-cara yang dilakukan untuk memperoleh data dan keteranganketerangan yang diperlukan dalam penelitian.

Teknik penentuan kriteria yang digunakan pada penelitian ini adalah dengan melakukan wawancara dengan pihak perusahaan mengenai teknik penentuan dan penilaian peserta lelang. Wawancara dilakukan terhadap pegawai perusahaan diantaranya 3 orang panitia lelang, 5 orang setingkat manajer dan supervisor dari 
perusahaan pusat dan 5 orang kepala bidang dari cabang. Selain itu pengumpulan data juga dilakukan dengan melakukan studi pustaka terkait dengan lelang terbuka dan kriteria yang digunakan untuk menentukan pemenang lelang tersebut.

Pengumpulan data dan seleksi awal dilakukan panitia lelang yang mendapat tugas dari perusahaan. Setelah data yang diperlukan lengkap, maka selanjutnya yang dilakukan adalah analisis data. Analisis data dilakukan data yang digunakan tepat dan benar-benar dapat menggambarkan kondisi peserta lelang saat ini, setelah itu baru dilakukan pengolahan data tersebut. (Al Azhar, 2010) Pengolahan data ialah melakukan penetapan kriteria yang digunakan dalam penelitian ini dan pemberian bobot pada setiap kriteria. Penentuan alternatif dan penentuan pemenang lelang menggunakan metode Topsis dan SMART. (Kristina, 2018) Setelah didapat hasil pengolahan data, maka selanjutnya dilakukan analisis perbandingan terhadap hasil dari metode metode tersebut.

\section{Penentuan Kriteria}

Berdasarkan ketentuan panitia lelang, setiap peserta lelang harus memenuhi berbagai persyaratan yang ditetapkan oleh perusahaan. Kriteria penentuan pemenang dari peserta lelang yang memasukan dokumen penawaran adalah sebagai berikut:

1) Pengalaman Peserta Lelang

a) Merencanakan pekerjaan sesuai kegiatan 7 tahun terakhir

b) Merencanakan pekerjaan mirip kegiatan 7 tahun terakhir

2) Kualifikasi Tenaga Ahli
a) Kualifikasi Team Leader
b) Kualifikasi Koordinator Tenaga Ahli
c) Kualifikasi Tenaga Ahli
d) Kualifikasi Tenaga Pendukung

3) Pemahaman Terhadap Kerangka Acuan Kerja (KAK)
a) Tujuan dan latar belakang proyek
b) Ruang lingkup proyek
c) Pengenalan kondisi wilayah
d) Potensi permasalahan

4) Pendekatan dan Metodologi
a) Desain fasilitas infrastruktur
b) Desain fasilitas bangunan
c) Apresiasi dan inovasi
d) Jadwal perencanaan

5) Fasilitas Pendukung
a) Fasilitas ruangan kantor
b) Fasilitas kendaraan
c) Perangkat keras komputer
d) Perangkat lunak software 
6) Paparan Konsep Desain (beauty contest)

a) Paparan persyaratan administratif

b) Paparan pemahaman atas KAK

c) Paparan metodologi dan inovasi

d) Paparan hasil kerja dan penjadwalan

Pada penentuan pemenang lelang terbuka ini menggunakan 6 kriteria yaitu pengalaman peserta lelang, kualifikasi tenaga ahli, pemahaman terhadap kerangka acuan kerja, pendekatan dan metodologi, fasilitas pendukung dan paparan konsep desain. Dari setiap kriteria dipilih satu hal yang dianggap paling bisa menggambarkan kriteria tersebut. Berikut ini merupakan kriteria yang digunakan untuk menentukan pemenang peserta lelang terbuka pekerjaan perencanaan rekayasa.

Tabel 1

Kriteria Seleksi Konsultan Desain Rekayasa

\begin{tabular}{|c|l|l|}
\hline Kriteria & \multicolumn{1}{|c|}{ Nama Kriteria } & \multicolumn{1}{c|}{ Uraian Kriteria } \\
\hline C1 & Pengalaman Peserta Lelang & Pengalaman pekerjaan sejenis selama 7 tahun terakhir \\
\hline C2 & Kualifikasi Tenaga Ahli & Kualifikasi Team Leader, Tenaga Ahli dan Tenaga Penunjang \\
\hline C3 & $\begin{array}{l}\text { Pemahaman Terhadap KAK } \\
\text { (Kerangka Acuan Kerja) }\end{array}$ & $\begin{array}{l}\text { Terutama terhadap tujuan dan latar belakang proyek, ruang lingkup, } \\
\text { pengenalan kondisi wilayah dan potensi permasalahan }\end{array}$ \\
\hline C4 & Pendekatan dan Metodologi & Konsep desain fasilitas dan rencana penjadwalan pekerjaan \\
\hline C5 & Fasilitas Pendukung & Fasilitas kantor, kendaraan dan software untuk proyek ini \\
\hline C6 & Paparan Konsep Desain & $\begin{array}{l}\text { Paparan/ presentasi tentang persyaratan administratif, pemahaman } \\
\text { terhadap KAK, metodologi, inovasi, hasil kerja dan penjadwalan }\end{array}$ \\
\hline
\end{tabular}

Mengacu pada tabel 1 di atas, selanjutnya masing-masing kriteria tersebut ditentukan bobotnya.

Tabel 2

\section{Bobot Kriteria Seleksi}

\begin{tabular}{|c|l|c|}
\hline Kriteria & \multicolumn{1}{|c|}{ Nama Kriteria } & Bobot \\
\hline C1 & Pengalaman Peserta Lelang & $6 \%$ \\
\hline C2 & Kualifikasi Tenaga Ahli & $16 \%$ \\
\hline C3 & $\begin{array}{l}\text { Pemahaman Terhadap KAK } \\
\text { (Kerangka Acuan Kerja) }\end{array}$ & $2 \%$ \\
\hline C4 & Pendekatan dan Metodologi & $14 \%$ \\
\hline C5 & Fasilitas Pendukung & $2 \%$ \\
\hline C6 & Paparan Konsep Desain & $60 \%$ \\
\hline
\end{tabular}

Pada setiap kriteria untuk setiap peserta lelang dinilai kelompok ahli, yang dibuat tiga kelompok, yaitu kelompok 1 yang menilai kriteria C1, C2 dan C5. Kelompok 2 yang menilai kriteria C3 dan C4. Sedangkan kelompok 3 yang menilai kriteria C6. Masing-masing kelompok terdiri dari 5 ahli. Rentang nilai yang digunakan dari nilai 
terendah 0 samapai dengan 100 . Nilai 0 jika peserta lelang tidak menyampaiakan materi yang diminta. Jika peserta lelang menyampaikan materi yang diminta namun tidak lengkap dan tidak bermutu maka diberi nilai terendah 30. Jika materi yang disampaikan sangat lengkap dan bermutu maka diberi nilai 90 sampai 100.

Setelah diketahui bobot dan nilai setiap kriteria, maka selanjutnya dapat melakukan proses penentuan pemenang lelang dengan metode Topsis dan SMART.

\section{Hasil dan Pembahasan}

Alternatif yang digunakan dalam penelitian ini merupakan 4 (empat) perusahaan konsultan desain tipe besar berbadan hukum berbentuk Perusahaan Terbatas (PT). Adapun gambaran kompetensi alternatif perusahaan tersebut adalah sebagai berikut:

\section{Tabel 3}

\section{Alternatif Perusahaan}

\begin{tabular}{|c|c|l|}
\hline No & Alternatif & \multicolumn{1}{c|}{ Kondisi Perusahaan Peserta Lelang } \\
\hline 1 & A1 & $\begin{array}{l}\text { Berpengalaman, tenaga ahli sedang sibuk, konsep desain } \\
\text { sangat baik. }\end{array}$ \\
\hline 2 & A2 & $\begin{array}{l}\text { Berpengalaman, tenaga ahli sedang sibuk, konsep desain } \\
\text { kurang lengkap. }\end{array}$ \\
\hline 3 & A3 & $\begin{array}{l}\text { Berpengalaman, tenaga ahli tersedia, konsep desain cukup } \\
\text { lengkap. }\end{array}$ \\
\hline 4 & A4 & $\begin{array}{l}\text { Kurang berpengalaman, tenaga ahli kurang, konsep desain } \\
\text { tidak lengkap. }\end{array}$ \\
\hline
\end{tabular}

Selain alternatif, yang diperlukan dalam perhitungan metode ini adalah bobot kriteria. Berdasarkan tabel 2, maka bobot preferensi adalah sebagai berikut: $\mathrm{W}=(0.06$, $0.16,0.02,0.14,0.02,0.60)$. Data mengenai kompetensi peserta lelang didapat dari dokumen lelang dan bahan paparan yang disampaikan kepada panitia lelang. Mengacu pada data dokumen lelang dan paparan yang telah diterima, maka rating kecocokan dari setiap alternatif pada setiap kriteria ditentukan sebagai berikut:

\section{Tabel 4}

Nilai Alternatif untuk Setiap Kriteria

\begin{tabular}{|c|c|c|c|c|c|c|c|}
\hline \multirow{2}{*}{ No } & \multirow{2}{*}{ Alternatif } & \multicolumn{7}{|c|}{ Nilai Kriteria } \\
\cline { 3 - 8 } & & C1 & C2 & C3 & C4 & C5 & C6 \\
\hline 1 & A1 & 80.06 & 60.87 & 88.76 & 77.27 & 87.76 & 80.85 \\
\hline 2 & A2 & 81.13 & 60.01 & 80.25 & 63.02 & 80.34 & 74.09 \\
\hline 3 & A3 & 90.18 & 88.97 & 85.64 & 76.12 & 88.57 & 85.79 \\
\hline 4 & A4 & 70.16 & 68.95 & 71.98 & 66.12 & 75.49 & 70.53 \\
\hline
\end{tabular}

Mengacu pada tabel 4, untuk C1 sampai nilai C6 nilai terbesar adalah terbaik maka diasumsikan sebagai kriteria keuntungan (benefit). Sehingga untuk melakukan 
normalisasi C1 sampai dengan C6 dilakukan normalisasi menggunakan persamaan yang menggunakan nilai maksimum.

Setelah matriks keputusan dibuat, maka selanjutnya dilakukan normalisasi terhadap matriks tersebut. Normalisasi terhadap matriks dilakukan dengan bantuan program Microsoft Excel. Jika diurutkan berdasarkan nilai tertinggi ke terendah maka urutannya sebagai berikut:

Tabel 5

Nilai Metode TOPSIS

\begin{tabular}{|c|c|c|c|}
\hline No & Peserta Lelang & Nilai Preferensi & Ranking \\
\hline $\mathbf{1}$ & $\mathbf{A 1}$ & 0.48767 & 2 \\
\hline $\mathbf{2}$ & $\mathbf{A 2}$ & 0.19526 & 3 \\
\hline $\mathbf{3}$ & $\mathbf{A 3}$ & 0.96478 & 1 \\
\hline $\mathbf{4}$ & $\mathbf{A 4}$ & 0.17917 & 4 \\
\hline
\end{tabular}

Mengacu pada tabel 5 di atas, dapat dilihat urutan nilai tertinggi sampai terendah untuk semua peserta lelang yang didapat dari metode TOPSIS, dengan urutan tertinggi A3, A1, A2, A4.

Tabel 6

Nilai Metode SMART

\begin{tabular}{|c|c|c|c|}
\hline No & Peserta Lelang & Nilai Preferensi & Ranking \\
\hline $\mathbf{1}$ & A1 & 0.80400 & 2 \\
\hline $\mathbf{2}$ & A2 & 0.74400 & 4 \\
\hline $\mathbf{3}$ & $\mathbf{A 3}$ & 0.85800 & 1 \\
\hline $\mathbf{4}$ & $\mathbf{A 4}$ & 0.75000 & 3 \\
\hline
\end{tabular}

Mengacu pada tabel 6 di atas, dapat dilihat urutan nilai tertinggi sampai terendah untuk semua peserta lelang yang didapat dari metode SMART, dengan urutan tertinggi A3, A1, A4, A2.

Tabel 7

Perbandingan Nilai

\begin{tabular}{|c|c|c|c|c|}
\hline \multirow{2}{*}{ No } & \multirow{2}{*}{ Alt } & \multicolumn{2}{|c|}{ METODE } & \multirow{2}{*}{ PERBANDINGAN } \\
\cline { 3 - 4 } & & TOPSIS & SMART & \\
\hline 1 & A1 & 0.48767 & 0.8040 & 1) Hasil ranking alternatif tertinggi sam untuk kedua metode. \\
\hline 2 & A2 & 0.19526 & 0.7440 & 2) Nilai metode $T O P S I S$ lebih kecil dari metode SMART. \\
\hline 3 & A3 & 0.96478 & 0.8580 & 3) Perbedaan nilai metode TOPSIS cukup besar. \\
\hline 4 & A4 & 0.17917 & 0.7500 & 4) Perbedaan nilai metode SMART sangat kecil. \\
\hline
\end{tabular}


Mengacu pada tabel 7 di atas, dapat dilihat perbandingan nilai untuk semua peserta lelang yang didapat dari metode TOPSIS dan SMART, yang ditampilkan pada kolom keterangan.

Dari kedua metode didapat urutan tertinggi A3, disusul A1, A2, A4 untuk metode TOPSIS, sedangkan metode SMART urutan tertinggi A3, disusul A1, A4 dan A2. Berdasarkan peringkat nilai tersebut di atas, para pengambil keputusan atau dalam hal ini pihak panitia lelang dapat mengambil keputusan perusahaan mana yang menjadi pemenangnya. Dalam hal ini peserta lelang yang menjadi pemenang adalah peserta A3.

\section{Kesimpulan}

Penelitian ini dilakukan dengan tujuan agar dapat mengetahui kriteria dan nilai bobot dari setiap kriteria dalam menentukan pemenang peserta lelang terbuka bidang rekayasa. Hasil dari penelitian ini adalah informasi mengenai peringkat nilai dari semua peserta lelang sehingga diharapkan hasil dari penelitian ini dapat dijadikan acuan perusahaan dalam menentukan pemenang lelang. Perusahaan peserta lelang dengan tingkat kompetensi terbaik yaitu perusahaan konsultan A3, baik yang didapat dari metode TOPSIS maupun SMART.

Kedua metode memberikan hasil urutan ranking yang sama untuk alternatif tertinggi dan kedua dengan urutan dari yang paling tinggi A3, disusul A1.

Saran yang diberikan untuk penelitian selanjutnya adalah diharapkan pada penelitian selanjutnya dapat dilakukan perhitungan peringkat peserta lelang dengan menggunakan metode yang lain, sehingga hasil analisis tersebut dapat menjadi pembanding dan pegangan untuk panitia lelang dalam menentukan pemenang lelang. 


\section{Bibliography}

Al Azhar, A. (2010). Peranan Total Quality Manajemen (TQM) Dalam Meningkatkan Daya Saing. PEKBIS (Jurnal Pendidikan Ekonomi Dan Bisnis), 2(01).

Chamid, A. A., \& Murti, A. C. (2017). Kombinasi Metode Ahp Dan Topsis Pada Sistem Pendukung Keputusan. Prosiding SNATIF, 115-119.

Daihani, D. U. (2001). Komputerisasi pengambilan keputusan. Jakarta: Elex Media Komputindo, 4.

Furqoni, F., Budi, D. S., \& Supriyanto, E. (2020). Bahasa Indonesia. Syntax Idea, 2(1), 43-47.

Kristina, T. (2018). Sistem Pendukung Keputusan Dengan Menggunakan Metode TOPSIS Untuk Pemilihan Lokasi Pendirian Grosir Pulsa. Paradigma, 20(1), 8-12.

Soipah, S. (2017). Perencanaan Arsitektur Sistem Informasi Koperasi Menggunakan Metodologi Togaf. Syntax Literate; Jurnal Ilmiah Indonesia, 2(11), 127-139.

Sugiyono, T., Sulistyorini, S., \& Rusilowati, A. (2017). Pengembangan perangkat pembelajaran ipa bervisi sets dengan metode outdoor learning untuk menanamkan nilai karakter bangsa. Journal of Primary Education, 6(1), 8-20.

Suyantoro, E. F. S. (2017). Konsep dan aplikasi sistem pendukung keputusan. Yogyakarta: Andi.

Widjaja, W. (2019). SISTEM PENDUKUNG KEPUTUSAN PEMILIHAN KONSULTAN DESAIN DENGAN METODE SIMPLE ADDITIVE WEIGHTING. Universitas, 1(6). 